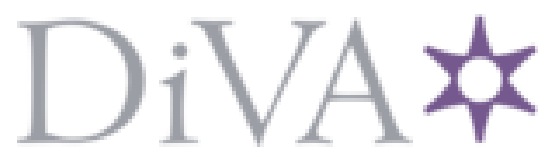

http://www.diva-portal.org

\title{
Postprint
}

This is the accepted version of a paper published in Synlett: Accounts and Rapid Communications in Synthetic Organic Chemistry. This paper has been peer-reviewed but does not include the final publisher proof-corrections or journal pagination.

Citation for the original published paper (version of record):

Merritt, E., Malmgren, J., Klinke, F., Olofsson, B. (2009)

Synthesis of diaryliodonium triflates using environmentally benign oxidizing agents.

Synlett: Accounts and Rapid Communications in Synthetic Organic Chemistry, (14): 2277-2280

http://dx.doi.org/10.1055/s-0029-1217723

Access to the published version may require subscription.

N.B. When citing this work, cite the original published paper.

Permanent link to this version:

http://urn.kb.se/resolve?urn=urn:nbn:se:su:diva-29387 


\title{
Synthesis of Diaryliodonium Triflates using Environmentally Benign
}

\section{Oxidizing Agents}

\author{
Eleanor A. Merritt, Joel Malmgren, Felix J. Klinke, Berit Olofsson* \\ Department of Organic Chemistry, Arrhenius Laboratory, Stockholm University, 10691 Stockholm, Sweden \\ Fax: $+46(8) 154908$ \\ E-mail: berit@organ.su.se
}

Received: The date will be inserted once the manuscript is accepted

\begin{abstract}
A range of symmetric and unsymmetric diaryliodonium triflates have been prepared employing urea-hydrogen peroxide as the oxidizing agent. The use of aqueous hydrogen peroxide and catalytic systems with MTO in the oxidation of iodoarenes has also been investigated.
\end{abstract}

Key words: hypervalent iodine, diaryliodonium salts, oxidation, arenes, green chemistry.

In recent years hypervalent iodine reagents have received considerable attention befitting their use as nontoxic and mild reagents in many areas of organic synthesis. ${ }^{1,2}$ Diaryliodonium salts have found applications in many reactions which traditionally employ transition metals, such as $\alpha$-arylation of carbonyl compounds ${ }^{3}$ and cross-coupling reactions, ${ }^{2,4}$ as iodine(III) reagents bearing two carbon ligands display similar properties to metals such as $\mathrm{Pd}, \mathrm{Hg}$ and $\mathrm{Pb}$. Replacement of heavy metals with diaryliodonium salts is highly beneficial from an environmental standpoint, providing a means to reduce both the cost and toxicity of these processes.

Diaryliodonium salts have the potential to render processes that currently employ heavy metals environmentally benign, provided that the synthesis of the salts themselves is sufficiently 'green'. Whilst efficient and operationally simple methodology for the preparation of such compounds has recently been developed within our laboratory (Scheme 1, method A), ${ }^{5,6}$ use of stoichiometric $m$-chloroperbenzoic acid ( $m$ CPBA) as oxidizing agent and the concomitant production of $m$ chlorobenzoic acid as waste make these protocols less desirable on an industrial scale. Other methods for the preparation of diaryliodonium salts have been reported, but they suffer from drawbacks such as the need to preform an iodine(III) species, ${ }^{7}$ extended reaction times, excess reagents ${ }^{9}$ or toxic chromium compounds. ${ }^{10}$

Encouraged by the previously reported use of ureahydrogen peroxide (UHP) in the synthesis of iodine(III) reagents, ${ }^{11}$ an investigation into the use of environmentally benign oxidizing agents in the synthesis of diaryliodonium triflates was undertaken. Triflate was the counterion of choice due to its poor nucleophilicity and the ease of purification by precipitation of the salts.

The initial investigation focused on replacing $m \mathrm{CPBA}$ (Scheme 1, method A) with either $30 \%$ aq. $\mathrm{H}_{2} \mathrm{O}_{2}$ or UHP (Scheme 1, method B). This approach proved largely unsuccessful, furnishing diphenyliodonium triflate (1a) with a maximum yield of $11 \%$, even after heating and prolonged reaction times.

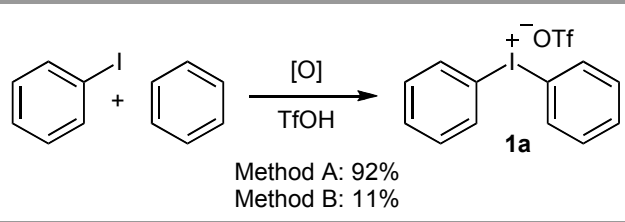

Scheme 1 Synthesis of 1a. Method A: ${ }^{6} m$ CPBA (1.1 equiv), TfOH (3 equiv) $\mathrm{CH}_{2} \mathrm{Cl}_{2}$, r.t., 10 min; Method B: urea- $\mathrm{H}_{2} \mathrm{O}_{2}$ (1.1 equiv), TfOH (3 equiv), $\mathrm{CH}_{2} \mathrm{Cl}_{2}, 40{ }^{\circ} \mathrm{C}, 3 \mathrm{~h}$.

As both Wirth ${ }^{11}$ and Kita ${ }^{12}$ have employed trifluoroacetic anhydride (TFAA) in the synthesis of iodine(III) reagents using hydrogen peroxide, the reaction was repeated with the addition of 2.5 equivalents of TFAA, improving the yield to $29 \%$ and demonstrating the need for activation of the peroxide prior to oxidation of the iodine. The procedure was then simplified to use only triflic anhydride $\left(\mathrm{Tf}_{2} \mathrm{O}\right)$ in place of the TfOH-TFAA mixture, in the hope that $\mathrm{Tf}_{2} \mathrm{O}$ would react with UHP to form triflic peroxide (2) in situ and that this reagent would be capable of efficiently oxidizing iodoarenes (Scheme 2). The intermediate iodine(III) compound would subsequently react with the arene by electrophilic aromatic substitution (EAS), forming diaryliodonium triflate 1 without need for an anion exchange. An intermediate similar to $\mathbf{2}$ was proposed by Kita ad co-workers for the reaction between TFAA and hydrogen peroxide ${ }^{12}$ and such perfluoroacyl peroxides have been observed and characterized by NMR studies. ${ }^{13}$

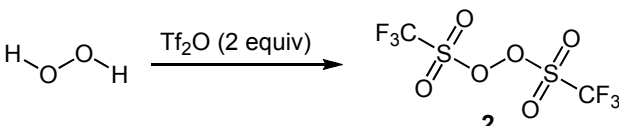

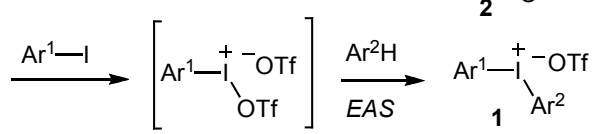

Scheme 2 Possible reaction intermediates in the synthesis of salts 1 with hydrogen peroxide and triflic anhydride.

The reaction was first conducted using Kita's anhydride:peroxide ratio of $8: 2$. The solvent of choice was 2,2,2-trifluoroethanol (TFE), ${ }^{12}$ which has been demonstrated to greatly enhance the yield of diaryliodonium salts prepared from preformed iodine(III) reagents. ${ }^{14}$ The reaction proved to be successful, furnishing the product in $24 \%$ yield after $24 \mathrm{~h}$ at room temperature (Table 1, entry 1). Fortunately, isolation of 1 a was straightforward 
also in the presence of urea; trituration of the concentrated crude mixture with diethyl ether afforded 1a as a colorless solid, with the residual urea remained in solution in the ether washings.

Subsequent optimization of the procedure is shown in Table 1. Increasing the temperature to $80{ }^{\circ} \mathrm{C}$ improved the yield to $62 \%$. The reaction time could be decreased to 3 hours without decreasing the yield (entry 4). Keen to improve upon the 'green chemistry' potential of the reaction, the $\mathrm{Tf}_{2} \mathrm{O}$ loading was reduced to 4 equivalents, further improving the yield of the reaction (entry 5). Continued reduction of the reagent amounts drastically reduced the yield of 1a (entries 6 and 7). Running the reaction in a 1:1 mixture of dichloromethane (DCM) and TFE yielded 1a in $69 \%$ yield (entry 8 ), rising to $82 \%$ in a 2:1 mixture of DCM and TFE (entry 9). As dichloromethane was now the major component of the solvent, the reaction temperature was reduced to $40{ }^{\circ} \mathrm{C}$ to circumvent the need for sealed tube reaction vessels. Gratifyingly, this did not have a majorly adverse effect on the yield of the reaction (entry 10).

\section{Table 1 Optimization of the synthesis of salt 1a}

\begin{tabular}{|c|c|c|c|c|c|c|}
\hline & 1 equiv & 2 equiv & $\frac{\text { urea- } \mathrm{H}_{2} \mathrm{O}_{2},}{\mathrm{Tf}_{2} \mathrm{O}}$ & 1 & & \\
\hline $\begin{array}{l}\text { En- } \\
\text { try }\end{array}$ & $\begin{array}{l}\text { UHP } \\
\text { (equiv) }\end{array}$ & $\begin{array}{l}\mathrm{Tf}_{2} \mathrm{O} \\
\text { (equiv) }\end{array}$ & Solvent & $\begin{array}{l}\mathrm{T} \\
\left({ }^{\circ} \mathrm{C}\right)\end{array}$ & $\begin{array}{l}\text { Time } \\
\text { (h) }\end{array}$ & $\begin{array}{l}\text { Yield } \\
(\%)^{\mathrm{a}}\end{array}$ \\
\hline 1 & 2 & 8 & TFE & r.t. & 24 & 24 \\
\hline 2 & 2 & 8 & TFE & 80 & 24 & 62 \\
\hline 3 & 2 & 8 & TFE & 80 & 1 & 50 \\
\hline 4 & 2 & 8 & TFE & 80 & 3 & 61 \\
\hline 5 & 2 & 4 & TFE & 80 & 3 & 72 \\
\hline 6 & 1.5 & 3 & TFE & 80 & 3 & 37 \\
\hline 7 & 1.1 & 2 & TFE & 80 & 3 & 38 \\
\hline 8 & 2 & 4 & DCM-TFE (1:1) & 80 & 3 & 69 \\
\hline 9 & 2 & 4 & DCM-TFE $(2: 1)$ & 80 & 3 & 82 \\
\hline 10 & 2 & 4 & DCM-TFE $(2: 1)$ & 40 & 3 & 76 \\
\hline 11 & 2 & 4 & DCM-TFE $(3: 1)$ & 40 & 3 & $90^{\mathrm{b}}$ \\
\hline 12 & 2 & 4 & DCM-TFE $(2: 1)$ & 40 & 2 & 22 \\
\hline 13 & 2 & 4 & DCM-TFE $(2: 1)$ & 40 & 6 & 65 \\
\hline 14 & 2 & 4 & DCM-TFE $(2: 1)$ & 40 & 3 & $60^{\mathrm{c}}$ \\
\hline 15 & 2 & 4 & $\mathrm{DCM}$ & 40 & 3 & 0 \\
\hline 16 & 2 & 4 & $\begin{array}{l}\text { DCM-EtOH } \\
(2: 1)\end{array}$ & 40 & 3 & 0 \\
\hline 17 & 2 & 4 & $\begin{array}{l}\text { DCM-HFIP }^{\mathrm{d}} \\
(2: 1)\end{array}$ & 40 & 3 & 0 \\
\hline
\end{tabular}

The use of a 3:1 ratio of DCM:TFE afforded the product, albeit contaminated with residual urea from the UHP (entry 11). Further alterations of reaction time or stoichiometry resulted in lower yields (entries 12-14).

In the absence of TFE, no reaction was observed and unreacted iodobenzene recovered (entry 15). Replacement of TFE with ethanol or hexafluoroisopropanol (HFIP) also led to the reisolation of iodobenzene and no formation of 1a (entries 16,17). This finding shows that TFE plays a vital role in this reaction, likely due to its capability of stabilizing the cationic intermediate obtained in the EAS reaction, although other mechanistic pathways cannot be excluded (vide infra). ${ }^{14,15}$

An alternative system for hydrogen peroxide activation was subsequently investigated to see whether triflic anydride could be replaced. Methylrhenium trioxide (MTO) is widely used in conjunction with hydrogen peroxide in a range of oxidation and epoxidation processes. $^{16}$ Unfortunately, all reactions employing MTO with either UHP or $30 \%$ aq. $\mathrm{H}_{2} \mathrm{O}_{2}$ failed, both in the presence and absence of triflic acid, universally returning iodobenzene. Addition of MTO to reactions containing triflic anhydride resulted in the formation of the characteristic yellow MTO- $\mathrm{H}_{2} \mathrm{O}_{2}$ complex, but no improvement in the yield was observed compared to reactions without MTO.

With an optimized method for the synthesis of 1 a (Table 1 , entry 10) in hand, the scope of the reaction was investigated by testing the compatibility of a range of substituted arenes and iodoarenes.

The synthesis of (4-iodophenyl)(phenyl)iodonium triflate (1b) proceeded smoothly under the standard reaction conditions, furnishing the desired product in $73 \%$ yield (Table 2, entry 2). The fluoro-analogue 1c was formed in $56 \%$ yield (entry 3 ), which surprisingly decreased to $46 \%$ after $6 \mathrm{~h}$. Reaction of iodobenzene with either bromobenzene (entry 4) or chlorobenzene (entry 6) resulted in formation of the desired product (1d and 1e respectively), contaminated with $\mathbf{1 b}$. This is likely due to the lower EAS-reactivity of bromo- and chlorobenzene relative to iodobenzene, combined with the slow oxidation of iodobenzene, thus formation of $\mathbf{1 b}$ competes with formation of the desired products.

In order to overcome this difficulty, the reactions were conducted using the relevant 4-haloiodobenzene and benzene. Contrary to the results obtained for salt 1c, longer reaction times considerably improved the yields, giving $1 \mathrm{~d}$ and $1 \mathrm{e}$ in $86 \%$ and $83 \%$ respectively (entries 5, 7). Symmetrical halogen-substituted salts $\mathbf{1 f}$ and $\mathbf{1 g}$ could also be prepared in high yields with prolonged reaction times (entries 8,9 ).

Electron-rich arenes could also be successfully employed, giving salts 1h-n (entries 10-16). The yields were as good or better when the reaction was performed at room temperature, which is in accordance with the reactivity pattern in electrophilic aromatic substitution reactions. The only exception was symmetric bis( $p$-tolyl) salt 1n, which was obtained in moderate yield upon heating and poor yield (4\%) at rt (entry 16). All attempts to employ very electron-rich or electron-poor arenes and iodoarenes, as well as heterocycles failed to yield identifiable products (entries 17-20).

In all cases, only the para-substituted product was observed. Removal of the residual urea by an aqueous 
workup proved to be necessary to precipitate some of the substituted salts.

\section{Table 2 Synthesis of substituted diaryliodonium salts}

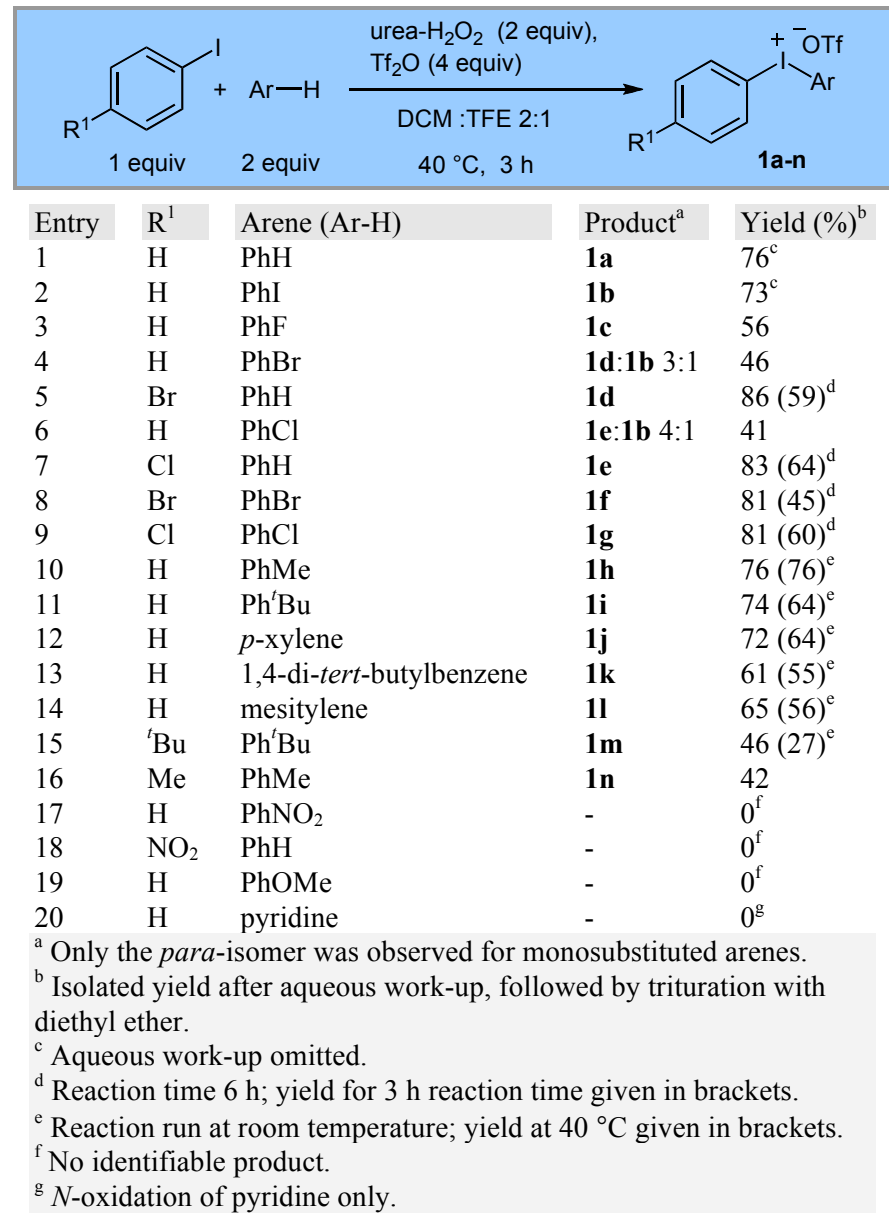

Preliminary investigations on the reaction mechanism were initiated after the observation of the comparatively poor yield of symmetrical tert-butyl salt $\mathbf{1 m}$ (entry 15), since this product has been obtained in good yield with the previously developed $m$ CPBA protocol. ${ }^{6}$

We decided to examine whether a free-radical process could be involved, either in formation of the product or in competing pathways leading to byproducts. Such a mechanism would also explain the vital influence of TFE, which is known to stabilize radical cation intermediates. ${ }^{14}$ Thus, the synthesis of $\mathbf{1 a}$ was repeated with exclusion of light, which made no significant difference. When the reaction was run in the presence of TEMPO (1 equiv) as a radical scavenger the salt was formed cleanly. Analysis of the crude reaction mixture by NMR spectroscopy and mass spectrometry showed that no additional aromatic byproducts were formed. Furthermore, products of side reactions between TEMPO and any triflate species could not be detected. This finding implies that a free-radical pathway is not operative in this reaction.

In summary, we have investigated the use of environmentally benign oxidizing agents in the synthesis of diaryliodonium salts and found that a range of both symmetric and unsymmetric salts can be prepared in good yields using urea-hydrogen peroxide, a safe and green reagent. The reaction is insensitive to air and moisture, and product isolation is straightforward, which makes this methodology easily applicable in large scale reactions.

\section{Representative synthetic procedures}

\section{Diphenyliodonium triflate (1a)}

A stirred 2:1 mixture of $\mathrm{CH}_{2} \mathrm{Cl}_{2}$ and TFE $(1 \mathrm{~mL})$ was cooled to $0{ }^{\circ} \mathrm{C}$ and UHP (47 mg, $\left.0.50 \mathrm{mmol}\right)$ was added. $\mathrm{Tf}_{2} \mathrm{O}(168 \mu \mathrm{L}, 1.00 \mathrm{mmol})$ was added dropwise to the suspension and the mixture was stirred for $30 \mathrm{~min}$ at 0 ${ }^{\circ} \mathrm{C}$. Iodobenzene $(28 \mu \mathrm{L}, 0.25 \mathrm{mmol})$ was added, followed by benzene $(45 \mu \mathrm{L}, 0.50 \mathrm{mmol})$ and the solution was warmed to room temperature, then heated at $40{ }^{\circ} \mathrm{C}$ for $3 \mathrm{~h}$. The mixture was allowed to cool to room temperature, evaporated in vacuo and the residue purified by trituration with diethyl ether $(3 \times 2 \mathrm{~mL})$ then dried in vacuo to afford the title compound $(82 \mathrm{mg}, 76 \%)$ as an off-white amorphous solid, spectroscopically identical with literature data. ${ }^{6}$

\section{( $p$-Tolyl)(phenyl)iodonium triflate (1h)}

Prepared according to the above procedure. The crude reaction mixture was allowed to cool to room temperature, evaporated in vacuo and the residue partitioned between dichloromethane $(5 \mathrm{~mL})$ and water $(5 \mathrm{~mL})$. The aqueous layer was further extracted with dichloromethane $(5 \mathrm{~mL})$ and the organic extracts combined and evaporated in vacuo. The residue was purified by trituration with diethyl ether $(3 \times 2 \mathrm{~mL})$ and dried in vacuo to afford the title compound ( $82 \mathrm{mg}, 76 \%$ ) as an off-white amorphous solid, spectroscopically identical with literature data. ${ }^{6}$

\section{Acknowledgment}

This work was financially supported by the Swedish Research Council, Wenner-Gren Foundations, Carl Trygger Foundation, the Royal Swedish Academy of Sciences and K \& A Wallenberg Foundation.

\section{References}

(1) (a) Wirth, T. Angew. Chem., Int. Ed. 2005, 44, 3656. (b) Stang, P. J. J. Org. Chem. 2003, 68, 2997. (c) Zhdankin, V. V.; Stang, P. J. Chem. Rev. 2008, 108, 5299. (d) Topics in Current Chemistry, Vol 224; Wirth, T., Ed.; Springer, Heidelberg, 2003.

(2) Phipps, R. J.; Gaunt, M. J. Science 2009, 323, 1593.

(3) (a) Beringer, F. M.; Daniel, W. J.; Galton, S. A.; Rubin, G. J. Org. Chem. 1966, 31, 4315. (b) Gao, P.; Portoghese, P. S. J. Org. Chem. 1995, 60, 2276. (c) Ryan, J. H.; Stang, P. J. Tetrahedron Lett. 1997, 38, 5061. (d) Aggarwal, V. K.; Olofsson, B. Angew. Chem., Int. Ed. 2005, 44, 5516.

(4) (a) Deprez, N. R.; Kalyani, D.; Krause, A.; Sanford, M. S. J. Am. Chem. Soc. 2006, 128, 4972. (b) Kalyani, D.; Deprez, N. R.; Desai, L. V.; Sanford, M. S. J. Am. Chem. Soc. 2005, 127, 7330. 
(5) (a) Zhu, M.; Jalalian, N.; Olofsson, B. Synlett 2008, 592. (b) Bielawski, M.; Olofsson, B. Chem. Commun. 2007, 2521. (c) Bielawski, M.; Aili, D.; Olofsson, B. J. Org. Chem. 2008, 73, 4602 .

(6) Bielawski, M.; Zhu, M.; Olofsson, B. Adv. Synth. Catal. 2007, $349,2610$.

(7) (a) Stang, P. J.; Zhdankin, V. V.; Tykwinski, R.; Zefirov, N. S. Tetrahedron Lett. 1991, 32, 7497. (b) Stang, P. J.; Zhdankin, V. V.; Tykwinski, R. Tetrahedron Lett. 1992, 33, 1419. (c) Koser, G. F.; Wettach, R. H.; Smith, C. S. J. Org. Chem. 1980, 45, 1543. (d) Zhdankin, V. V.; Scheuller, M. C.; Stang, P. J. Tetrahedron Lett. 1993, 34, 6853. (e) Zefirov, N. S.; Kasumov, T. M.; Koz'min, A. S.; Sorokin, V. D.; Stang, P. J.; Zhdankin, V. V. Synthesis 1993, 1209. (f) Kitamura, T.; Matsuyuki, J.; Taniguchi, H. Synthesis 1994, 147. (g) Kitamura, T.; Kotani, M.; Fujiwara, Y. Tetrahedron Lett. 1996, 37, 3721. (h) Shah, A.; Pike, V. W.; Widdowson, D. A. J. Chem. Soc. Perkin Trans. 1 1997, 2463. (i) Ochiai, M.; Nakanishi, A.; Yamada, A. Tetrahedron Lett. 1997, 38, 3927. (j) Carroll, M. A.; Pike, V. W.; Widdowson, D. A. Tetrahedron Lett. 2000, 41, 5393.

(8) Hossain, M. D.; Kitamura, T. Tetrahedron 2006, 62, 6955.

(9) Kryska, A.; Skulski, L. Molecules 2001, 6, 875.

(10) Kaźmierczak, P.; Skulski, L. Synthesis 1995, 1027.

(11) Page, T. K.; Wirth, T. Synthesis 2006, 3153.

(12) Dohi, T.; Minamitsuji, Y.; Maruyama, A.; Hirose, S.; Kita, Y. Org. Lett. 2008, 10, 3559.

(13) Krasutsky, P. A.; Kolomitsyn, I. V.; Carlson, R. M. Org. Lett. 2001, 3, 2997.

(14) Dohi, T.; Ito, M.; Morimoto, K.; Minamitsuji, Y.; Takenaga, N.; Kita, Y. Chem. Commun. 2007, 4152.

(15) Neimann, K.; Neumann, R. Org. Lett. 2000, 2, 2861.

(16) Modern Oxidation Methods; Bäckvall, J. E., Ed.; WileyVCH: Weinheim, 2004. 
Synthesis of Diaryliodonium Triflates using Hydrogen Peroxide

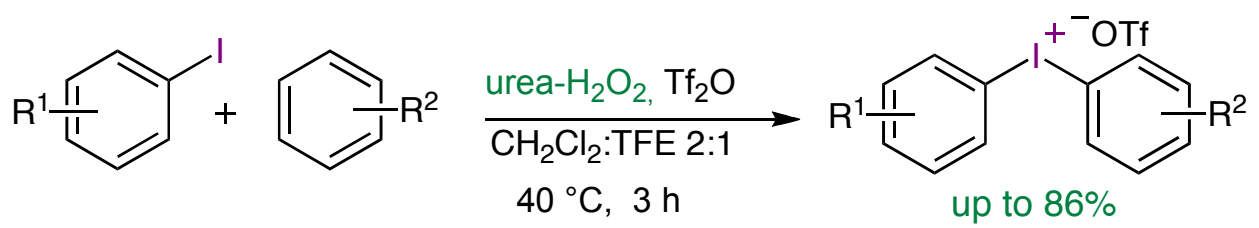

